\title{
Spanish laboratory backs off bid to cut research staff
}

\section{Snapshot of French science shows growing impact}

\begin{abstract}
Madrid. Spain's Council for Scientific Research (CSIC) last week backed down on a decision to eliminate the posts of 14 researchers from the Biological Research Centre (CIB) in Madrid, the largest of its hundred or so institutes.

The council has apparently bowed to pressure from the scientists to reverse a decision taken after two independent evaluations had given them low scores for productivity, and the former director of the institute had recommended that they be "re-
\end{abstract} located" elsewhere.

The decision is a blow to CSIC's attempts to boost the productivity of its centres by penalizing scientists whose output is felt to be unacceptably low. Last February, the council changed its rules to increase the power of institute directors over the way their laboratories are organized, and to reduce the involvement of staff in management decisions.

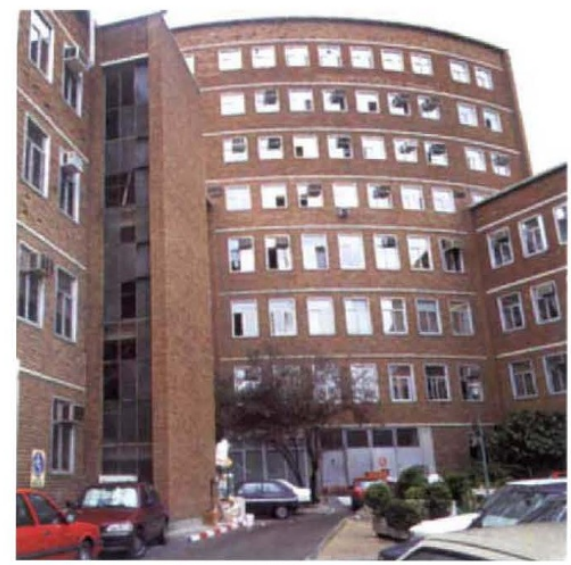

Madrid's Biological Research Centre
Most of these scientists had been in charge of small groups whose performance was considered by the evaluation committees to be particularly low. Between them they brought in less than 5 per cent of the institute's grant income and published far less than other scientists on the centre's staff. Espinosa proposed that they should be transferred to other CSIC institutes.

But the scientists involved challenged the report's conclusion, backed by the Association of CSIC Staff Researchers, the professional association to which 30 per cent of CSIC's researchers are affiliated.

The controversy provoked a second evaluation by a new committee in July. This supported the original committee's conclusions. But the CIB scientists continued to oppose Espinosa's plans for reorganization, and led a public campaign against them.

The situation changed in the last

The impact of these changes has already been felt by researchers at the Cajal Institute of Neurobiology in Madrid, whose 160 staff members include 35 scientists. After an evaluation in January 1992, the institute was reorganized into four departments, and four researchers whose productivity was considered to be very low lost some of their technical staff and laboratory space.

The centre's director, Alberto Ferrús, says that the decision was painful, but was necessary to improve the scientific performance of the whole institute. Similar changes are now feared at the CIB, which has 500 staff, including 86 scientists. The centre was widely known in the 1960s and 1970s for its work in enzymology and molecular biology, but since then its scientific productivity has not grown as fast as hoped.

In March 1992, an external evaluation committee complained that the institute had no strategic plan, was split into groups that were too small to carry out internationally competitive work, and did not have enough young scientists.

In response, the institute's then acting director, Manolo Espinosa, announced plans to reorganize CIB into five departments. One proposal, apparently backed by CSIC, was that the positions of 14 researchers would disappear because, it was claimed, their work did not fit into the new scheme. week of September when Espinosa's tempoGuillermo Jimenez, who had worked for several years in the institute, was appointed.

Jimenez revoked Espinosa's plans - once again with the backing of CSIC - and redistributed the 14 researchers within the new departments, allowing them to keep the laboratory space and technical assistance they had enjoyed before the evaluations.

The decisions of the new director are widely seen as CSIC's response to pressure from the scientists' union. But the changes recently introduced by CSIC in the way that research institutes are run in Spain are still considered by many scientists necessary to increase their effectiveness.

The new rules, introduced earlier this year after seven years of debate, increase the power of the directors, as well as of the boards. The rules also reduce the presence of researchers on CSIC's 24-member scientific and executive advisory boards.

The latter move has itself provoked widespread criticism from some researchers, who claim that the institutes are becoming less democratic. But others feel that what has happened at CIB shows that the reorganization process is itself in danger of becoming ineffective.

Oscar G. Segurado rary contract expired and a new director, president of the CSIC itself and its advisory
Paris. Spending on science in France increased from 1.97 to 2.4 per cent of the country's gross national product during the 1980 s, a reflection of the priority given to research by the Socialist government which came to power in 1981, according to the second report of the Observatoire des Sciences et des Techniques (OST).

This increase in funding was accompanied by a 10 per cent rise in France's share of publications in international journals to 4.7 per cent (although some of this increase may be accounted for by the trend to publish more in English). In contrast, over the same period, the United Kingdom's share fell by 8 per cent to 8.4 per cent, and Germany's by 5 per cent to 6.2 per cent.

The OST report is the French equivalent of the Science and Engineering Indicators produced by the National Science Board in the United States, with more than 350 tables of statistics on French research and its position compared to the rest of the world.

If the report provides evidence of the impact of increased spending on research during the $1980 \mathrm{~s}$, it also provides information that is likely to help politicians to decide where best to reduce spending in the country's current economic crisis.

In particular, because the breakdown of public spending on science is by theme rather than by research organizations, it is able to reveal the continued preoccupation with defence and strategic technologies which began with de Gaulle in the 1950s.

More than half the FF86 billion(US\$14.6 billion) public spending on both civilian and military research goes on four large programmes: space, aeronautics, telecommunications and nuclear. The clear implication is that the government might do better to reduce its spending on large programmes rather than imposing, as it has done, almost zero-budget growth on research organizations in next year's budget (see Nature 365, 598; 1993).

Rémi Barre, the director of OST, says that the high level of spending on these large programmes also challenges the widely held assumption that France spends more than other European countries of its science budget on public sector projects.

Health, transport and the environment, for example, accounted for less than 10 per cent of the total national spending on research by both government and industry (FF158.7 billion). Similarly, funding on technology transfer and innovation over the same period amounted to just one per cent of total spending on science. Declan Butler

Science \& Technologie Indicateurs 1994, (OST, 93 rue du Vaugiraud, 75014, Paris) 